\title{
Association of lunch meat consumption with nutrient intake, diet quality and health risk factors in U.S. children and adults: NHANES 2007-2010
}

Sanjiv Agarwal ${ }^{*}$, Victor L. Fulgoni $1 \|^{2}$ and Eric P. Berg ${ }^{3}$

\begin{abstract}
Background: Consumption of lean meat is recommended as part of healthy diet by Dietary Guidelines for Americans, 2010. Lunch meats are precooked or cured meats typically used in sandwiches and are also called as cold cuts or deli meat.

Objective: The purpose of the study was to examine the association of lunch meat consumption with nutrient intake, diet quality, and physiological measures in children (age $2-18$ years; $n=5,099$ ) and adults (age 19 years and older; $n=10,216$ ) using a large, nationally representative database.

Methods: Lunch meat consumers were defined as those consuming any amount of lunch meat during a 24-h recall and association with nutrient intake, diet quality (Healthy Eating Index (HEI)-2010 score) and physiological measures were evaluated using the National Health and Nutrition Examination Survey (NHANES), 2007-2010.

Results: The lunch meat consumers (both children and adults) had higher intakes of calories, protein, calcium, potassium, sodium and saturated fat (for adults only) compared to non-consumers. Lunch meat intake was also associated with higher intake of meat/poultry/fish food group in both children and adult consumers than non-consumers. There was no difference in total HEl-2010 scores comparing lunch meat consumers and non-consumers in children or adults. However, HEl components scores for total fruit, whole fruit (children only), whole grains, dairy and total protein foods were significantly higher, and for greens \& beans (adults only), seafood and plant protein, fatty acid ratio and sodium were significantly lower in children and adult lunch meat consumers compared to non-consumers. There were no significant differences in physiological measures or in the odds ratios of health related conditions between lunch meat consumers and non-consumers in children or adults.
\end{abstract}

Conclusions: The results of this study may provide insight into how to better utilize lunch meats in the diets of U.S. children and adults.

Keywords: Lunch meat, NHANES, Nutrients, Diet quality, Health risk factors

\section{Background}

The Dietary Guidelines for Americans, 2010 recommend consumption of lean meat as part of an overall healthy diet [1]. MyPlate (ChooseMyPlate.gov) recommends intake from the meat and beans group ranges from 2 to 6.5 ounce (oz.) equivalents depending on age, gender, and physical activity [2]. Meat is an important source of

\footnotetext{
* Correspondence: agarwal47@yahoo.com

'NutriScience LLC, 901 Heatherwood Drive, East Norriton, PA 19403, USA

Full list of author information is available at the end of the article
}

high quality protein and several key micronutrients including iron, zinc, and B-vitamins in American diet [1-8]. The bioavailability of iron and folate from meat is higher than from plant products such as grains and leafy green vegetables $[3,9]$.

Lunch meats are precooked or cured meats that are sliced for use in sandwich or salad toppings. They are also referred to as "cold cuts" or "deli meat". There are three types of lunch meats: a) Whole cut - a section of whole muscle that is cooked, flavored/spiced and sliced 
such as roast beef or corned beef; b) Sectioned/formed meat trimmings or flakes bound together to form restructured meat products such as multi-part turkey breast or cooked ham; and c) Processed meat - which include fine or coarsely ground meat products such as sausages or emulsified products such as bologna and hot dogs. The recently released Scientific Report of the Dietary Guidelines Advisory Committee 2015 indicated that dietary patterns consisting of lower consumption of red and processed meat were associated with positive health outcomes [10].

The purpose of the present study was to assess the association of lunch meat intake with nutrient intake, diet quality and physiological measures associated with health risk factors in children and adults using a large nationally representative database.

\section{Methods}

\section{Subjects}

National Health and Nutrition Examination Survey (NHANES), a large dietary survey of a nationally representative sample of the non-institutionalized US population, was used to assess lunch meat intake [11]. The NHANES data are collected and released by the National Center for Health Statistics (NCHS) of the Center for Disease Control and Prevention, every two years. All participants or proxies (i.e., parents or guardians) provided written informed consent and the Research Ethics Review Board at the NCHS approved the survey protocol. Dietary intake data with reliable 24-h recall dietary interviews (day 1 data only) using United States Department of Agriculture's (USDA) automated multiple-pass method were used. The data from NHANES 2007-2008 and 2009-2010 were combined for the analyses [11]. The combined sample included 5,099 children age $2-18$ years old and 10,216 adults age 19 years and older excluding pregnant and/or lactating females and those with incomplete or unreliable 24-h recall data.

\section{Estimation of intake}

Lunch meat intakes were assessed using a total of thirty nine USDA food codes for typical lunch meats (Table 1) $[12,13]$. These food codes were also used to find food codes containing luncheon meat as an ingredient. Foods such as stews containing small amounts $(<7 \%)$ of luncheon meats as ingredient were not considered as lunch meat. Lunch meat consumers were defined as those

Table 1 USDA food codes for lunch meats and their description $[12,13]$

\begin{tabular}{|c|c|c|c|}
\hline Food code & Description & Food code & Description \\
\hline 21420100 & Beef, sandwich steak (flaked, formed, thinly sliced) & 25230310 & Chicken or turkey loaf, prepackaged or deli, luncheon meat \\
\hline 21603000 & Beef, pastrami (beef, smoked, spiced) & 25230410 & Ham loaf, luncheon meat \\
\hline 22311450 & Ham, prosciutto & 25230430 & Ham and cheese loaf \\
\hline 25220010 & Cold cut, NFS & 25230510 & Ham, luncheon meat, chopped, minced, pressed, spiced, not canned \\
\hline 25220390 & Bologna, beef, low fat & 25230520 & $\begin{array}{l}\text { Ham, luncheon meat, chopped, minced, pressed, spiced, low fat, } \\
\text { not canned }\end{array}$ \\
\hline 25220400 & Bologna, pork and beef & 25230530 & $\begin{array}{l}\text { Ham and pork, luncheon meat, chopped, minced, pressed, spiced, } \\
\text { canned }\end{array}$ \\
\hline 25220410 & Bologna, NFS & 25230540 & $\begin{array}{l}\text { Ham, pork and chicken, luncheon meat, chopped, minced, pressed, } \\
\text { spiced, canned }\end{array}$ \\
\hline 25220420 & Bologna, Lebanon & 25230550 & $\begin{array}{l}\text { Ham, pork, and chicken, luncheon meat, chopped, minced, pressed, } \\
\text { spiced, canned, reduced sodium }\end{array}$ \\
\hline 25220430 & Bologna, beef & 25230560 & Liverwurst \\
\hline 25220440 & Bologna, turkey & 25230610 & Luncheon loaf (olive, pickle, or pimiento) \\
\hline 25220470 & Bologna, beef, lower sodium & 25230710 & Sandwich loaf, luncheon meat \\
\hline 25220480 & Bologna, chicken, beef, and pork & 25230790 & Turkey ham, sliced, extra lean, prepackaged or deli, luncheon meat \\
\hline 25220500 & Bologna, beef and pork, low fat & 25230800 & Turkey ham \\
\hline 25221500 & Salami, NFS & 25230810 & Veal loaf \\
\hline 25221510 & Salami, soft, cooked & 25230820 & Turkey pastrami \\
\hline 25221520 & Salami, dry or hard & 25230840 & Turkey salami \\
\hline 25230110 & Luncheon meat, NFS & 25230900 & Turkey or chicken breast, prepackaged or deli, luncheon meat \\
\hline 25230210 & Ham, sliced, prepackaged or deli, luncheon meat & 25230905 & Turkey or chicken breast, low salt, prepackaged or deli, luncheon meat \\
\hline 25230220 & $\begin{array}{l}\text { Ham, sliced, low salt, prepackaged or deli, } \\
\text { luncheon meat }\end{array}$ & 25231110 & Beef, sliced, prepackaged or deli, luncheon meat \\
\hline 25230230 & $\begin{array}{l}\text { Ham, sliced, extra lean, prepackaged or deli, } \\
\text { luncheon meat }\end{array}$ & & \\
\hline
\end{tabular}


consuming any amount of lunch meat (from 39 food codes) during a 24-h recall. Energy and nutrient intake were determined using the USDA Nutrient Database for Standard Reference Releases 22 and 24 in conjunction with the Food \& Nutrient Database for Dietary Studies versions 4.1 and 5.0, for NHANES 2007-2008 and NHANES 2009-2010 participants respectively [12-15]. The USDA Food Patterns Equivalents Database (FPED) [16] was used to calculate intake MyPlate [17] servings. The FPED translates dietary recall data into equivalent servings of the seven MyPlate major food groups and corresponding subgroups. The number of MyPlate servings was aggregated over all foods consumed during the 24-hour recall to calculate the MyPlate food group intakes per day.

\section{Estimation of diet quality}

Diet quality was calculated using the Healthy Eating Index (HEI) -2010 which has 12 components, each representing a different aspect of diet quality [18]. HEI - 2010 scores were estimated using day 1 dietary intake data. The SAS code used to calculate HEI - 2010 scores was downloaded from the USDA website [19].

\section{Estimation of physiological markers of risk}

Health indices evaluated included body weight, body mass index (BMI) and Z score for children [20], as well as BMI, waist circumference, blood pressure, fasting plasma glucose, fasting plasma insulin, c-reactive protein, fasting triglycerides, total cholesterol, LDL-cholesterol (fasting), HDL-cholesterol, and apolipoprotein B, and risk of metabolic syndrome for adults using NHANES standard protocols [11]. For a variety of reasons, not all individuals have values for all tests (see tables for sample numbers). Metabolic syndrome was defined using the NHLBI Adult Treatment Panel III criteria [21], namely having three or more of the following risk factors: abdominal obesity (waist circumference $>102 \mathrm{~cm}$ for males and $>88 \mathrm{~cm}$ for females); hypertension (BP systolic $\geq 130 \mathrm{mmHg}$ or BP diastolic $\geq 85 \mathrm{mmHg}$ or taking anti-hypertensive medications); low HDL-cholesterol ( $<40 \mathrm{mg} / \mathrm{dL}$ for males and $<50 \mathrm{mg} / \mathrm{dL}$ for females); high triglycerides $(\geq 150 \mathrm{mg} / \mathrm{dL}$ or taking anti-hyperlipidemic medications); high fasting glucose $(\geq 110 \mathrm{mg} / \mathrm{dL}$ or taking insulin or other hypoglycemic agents).

\section{Statistical analysis}

All analyses were performed using SAS 9.2 (SAS Institute, Cary, NC) and SUDAAN 11 (RTI, Research Triangle Park, $\mathrm{NC}$ ) to adjust the variances for the complex sample design of NHANES and thus survey weights, strata and primary sampling units were used in all calculations. Day one dietary weights were used in all intake analyses, while the Mobile Examination Center weights were used for physiological variables except where the outcome was a fasting lab variable in which case fasting subsample weights were used. Least square means (Mean), standard errors of the mean (SEM), via regression analyses were determined for energy and nutrient intakes, food group intake, diet quality, and physiological markers of metabolic disease risk in lunch meat consumers and non-consumers. Food group/nutrient intakes were adjusted for age (even within each age group), gender, ethnicity, poverty income ratio, self-reported physical activity level, smoking status, alcohol intake (only for adults), and energy intake (except for energy intake). Diet quality was adjusted for the same covariates but without energy intake as HEI scores are already adjusted for energy intake. Physiological variables were adjusted for age, gender, ethnicity, poverty-income ratio, self-reported physical activity level, smoking status, alcohol intake (only for adults) and BMI (for non-weight related variables).

\section{Results}

Approximately $19.4 \%$ adults (age 19 years and older) and $17.8 \%$ children (age 2-18 years) were lunch meat consumers. In both children and adults, there were no major demographic differences between lunch meat consumers and non-consumers except that there were $12 \%$ fewer adult female consumers $(46.2 \%$ female adult consumers versus $52.6 \%$ female non-consumers, $P<0.0001$ ).

There were significant differences in nutrient intakes between the lunch meat consumers and the nonconsumers (Table 2). Compared with non-consumers in children, lunch meat consumers had significantly higher $(P<0.01)$ intakes of calories $(7.3 \%)$, and energy adjusted daily intakes of protein $(8.3 \%)$, calcium (13\%), potassium (5.5\%), thiamin (7.3\%) and sodium (15.6\%). Similarly adult lunch meat consumers also had significantly higher $(P<0.01)$ intakes of calories $(4.4 \%)$, and energy adjusted intakes of protein (6.3\%), saturated fatty acids (3.6\%), calcium (14.3\%), potassium (6.2\%), thiamin (11.1\%), and sodium (18.3\%) compared to adult nonconsumers. Adult lunch meat consumers also had significantly lower $(P<0.01)$ intakes of monounsaturated fatty acids (MUFA) $(-3.6 \%)$ and polyunsaturated fatty acids (PUFA) $(-4.5 \%)$ compared to non-consumers. The intake of other nutrients was not significantly different among lunch meat consumers and non-consumers (Table 2).

Intake of lunch meat was also associated with significant differences $(P<0.01)$ in specific MyPlate food groups (Table 3). Significantly higher intakes of meat/ poultry/fish (31.8\%) and whole grain (37.1\%), and lower intake of added sugars $(-7.5 \%)$ were observed among children consuming lunch meats compared to nonconsumers. Among adults, consumers of lunch meat 
Table 2 Energy and nutrient intakes in children $(n=5099)$ and adult $(n=10216)$ lunch meat consumers and non-consumers (NHANES 2007-2010, gender combined data). Values are means \pm SEM. Values are adjusted for age, gender, ethnicity, poverty income ratio, physical activity level, current smoking status, alcohol (only for adults), and kcal (except for energy)

\begin{tabular}{|c|c|c|c|c|c|c|}
\hline \multirow[t]{2}{*}{ Variables } & \multicolumn{3}{|c|}{ Children ( $2-18$ years old) } & \multicolumn{3}{|c|}{ Adults (19 years and older) } \\
\hline & Non-consumers & Consumers & $P$ Value for difference & Non-consumers & Consumers & $P$ Value for difference \\
\hline Energy (kcal) & $1873 \pm 17$ & $2009 \pm 42$ & 0.0022 & $2115 \pm 14$ & $2209 \pm 27$ & 0.0029 \\
\hline Protein (gm) & $66.6 \pm 0.4$ & $72.1 \pm 1.0$ & $<0.0001$ & $81.6 \pm 0.4$ & $86.8 \pm 0.8$ & $<0.0001$ \\
\hline Carbohydrate (gm) & $255 \pm 1$ & $250 \pm 2$ & 0.0236 & $258 \pm 1$ & $254 \pm 2$ & 0.0122 \\
\hline Dietary fiber (gm) & $13.0 \pm 0.2$ & $12.9 \pm 0.2$ & 0.7796 & $16.5 \pm 0.3$ & $15.7 \pm 0.3$ & 0.0147 \\
\hline Total sugars (gm) & $127 \pm 1.3$ & $122 \pm 2$ & 0.0201 & $118 \pm 1$ & $114 \pm 2$ & 0.0253 \\
\hline Total fat (gm) & $69.6 \pm 0.4$ & $69.6 \pm 1.0$ & 0.9627 & $80.3 \pm 0.4$ & $79.6 \pm 0.6$ & 0.2920 \\
\hline MUFA (gm) & $25.1 \pm 0.2$ & $24.2 \pm 0.5$ & 0.0647 & $29.4 \pm 0.2$ & $28.4 \pm 0.3$ & 0.0016 \\
\hline PUFA (gm) & $14.0 \pm 0.2$ & $13.8 \pm 0.3$ & 0.4677 & $17.5 \pm 0.1$ & $16.8 \pm 0.2$ & 0.0008 \\
\hline SFA (gm) & $24.4 \pm 0.2$ & $25.3 \pm 0.6$ & 0.1387 & 26.3 & $27.2 \pm 0.3$ & 0.0021 \\
\hline Cholesterol (mg) & $210 \pm 3$ & $228 \pm 8$ & 0.0269 & $287 \pm 4$ & $277 \pm 5$ & 0.0944 \\
\hline Calcium (mg) & $1006 \pm 12$ & $1136 \pm 29$ & 0.0006 & $953 \pm 9$ & $1090 \pm 16$ & $<0.0001$ \\
\hline Iron (mg) & $13.5 \pm 0.2$ & $13.8 \pm 0.4$ & 0.3901 & $15.2 \pm 0.1$ & $15.3 \pm 0.2$ & 0.5789 \\
\hline Magnesium (mg) & $228 \pm 2$ & $235 \pm 5$ & 0.1177 & $299 \pm 3$ & $302 \pm 3$ & 0.4044 \\
\hline Potassium (mg) & $2141 \pm 22$ & $2258 \pm 37$ & 0.0020 & $2674 \pm 22$ & $2839 \pm 26$ & $<0.0001$ \\
\hline Sodium (mg) & $2966 \pm 28$ & $3427 \pm 52$ & $<0.0001$ & $3494 \pm 18$ & $4132 \pm 43$ & $<0.0001$ \\
\hline Vitamin A $(\mu \mathrm{g})$ & $592 \pm 10$ & $591 \pm 19$ & 0.9744 & $621 \pm 9$ & $637 \pm 15$ & 0.2720 \\
\hline ß-carotene $(\mu \mathrm{g})$ & $1171 \pm 61$ & $1136 \pm 137$ & 0.8192 & $2081 \pm 62$ & $2002 \pm 116$ & 0.4936 \\
\hline Thiamin (mg) & $1.5 \pm 0.02$ & $1.6 \pm 0.03$ & 0.0012 & $1.6 \pm 0.02$ & $1.8 \pm 0.03$ & $<0.0001$ \\
\hline Total Folate $(\mu \mathrm{g})$ & $360 \pm 5$ & $361 \pm 17$ & 0.9696 & $409 \pm 5$ & $403 \pm 6$ & 0.4370 \\
\hline Vitamin B6 (mg) & $1.7 \pm 0.03$ & $1.8 \pm 0.1$ & 0.2082 & $2.0 \pm 0.02$ & $2.1 \pm 0.04$ & 0.0302 \\
\hline Vitamin C (mg) & $78.6 \pm 1.9$ & $86.5 \pm 4.4$ & 0.0763 & $86.2 \pm 2.1$ & $83.5 \pm 2.3$ & 0.2940 \\
\hline
\end{tabular}

MUFA monounsaturated fatty acids, PUFA polyunsaturated fatty acids, SFA saturated fatty acids

Table 3 Intake of MyPlate food groups in children $(n=5099)$ and adult $(n=10216)$ lunch meat consumers and non-consumers (NHANES 2007-2010, gender combined data). Values are means \pm SEM. Values are adjusted for age, gender, ethnicity, poverty income ratio, physical activity level, current smoking status, alcohol (only for adults), and kcal

\begin{tabular}{|c|c|c|c|c|c|c|}
\hline \multirow[t]{2}{*}{ Variables } & \multicolumn{3}{|c|}{ Children (2-18 years old) } & \multicolumn{3}{|c|}{ Adults (19 years and older) } \\
\hline & Non-consumers & Consumers & $P$ Value for difference & Non-consumers & Consumers & $P$ Value for difference \\
\hline Total Fruit (cup eq.) & $1.08 \pm 0.04$ & $1.23 \pm 0.06$ & 0.0102 & $0.99 \pm 0.03$ & $1.07 \pm 0.04$ & 0.0241 \\
\hline Whole Fruit (cup eq.) & $0.67 \pm 0.04$ & $0.78 \pm 0.06$ & 0.0252 & $0.67 \pm 0.02$ & $0.76 \pm 0.03$ & 0.0318 \\
\hline Fruit Juice (cup eq.) & $0.41 \pm 0.02$ & $0.44 \pm 0.04$ & 0.3352 & $0.31 \pm 0.01$ & $0.31 \pm 0.03$ & 0.9484 \\
\hline Total Vegetable (cup eq.) & $0.90 \pm 0.03$ & $0.81 \pm 0.03$ & 0.0362 & $1.58 \pm 0.03$ & $1.46 \pm 0.03$ & 0.0042 \\
\hline Total Grain (oz eq.) & $6.32 \pm 0.07$ & $6.67 \pm 0.15$ & 0.0286 & $6.37 \pm 0.06$ & $6.75 \pm 0.10$ & 0.0027 \\
\hline Whole Grain (oz eq.) & $0.53 \pm 0.02$ & $0.73 \pm 0.04$ & 0.0003 & $0.72 \pm 0.03$ & $0.94 \pm 0.04$ & $<0.0001$ \\
\hline Total Dairy (cup eq.) & $2.17 \pm 0.04$ & $2.33 \pm 0.10$ & 0.2019 & $1.61 \pm 0.02$ & $1.90 \pm 0.04$ & $<0.0001$ \\
\hline Milk (cup eq.) & $1.44 \pm 0.03$ & $1.25 \pm 0.05$ & 0.0129 & $0.85 \pm 0.02$ & $0.86 \pm 0.03$ & 0.9151 \\
\hline Meat/Poultry/Fish (oz eq.) & $3.21 \pm 0.08$ & $4.23 \pm 0.12$ & $<0.0001$ & $4.70 \pm 0.06$ & $6.14 \pm 0.08$ & $<0.0001$ \\
\hline Added Sugar (tsp eq.) & $19.4 \pm 0.3$ & $17.9 \pm 0.4$ & 0.0092 & $18.5 \pm 0.4$ & $17.5 \pm 0.5$ & 0.0264 \\
\hline
\end{tabular}


had higher intakes of meat/poultry/fish (30.6\%), whole grain $(30.7 \%)$, dairy $(17.9 \%)$ and grains $(5.9 \%)$, and lower intake of vegetables $(-7.6 \%)$ compared to adult non-consumers.

Despite some differences in food groups intake, there was no difference in dietary quality (measured by the HEI-2010) comparing lunch meat consumers and nonconsumers for children (HEI-2010 scores difference between consumers and non-consumers: $-0.30, P=0.6187$ ) or adults (HEI-2010 scores difference between consumers and non-consumers: $-0.61, P=0.2010$ ) (Table 4). When the data were further analyzed for different age groups for children and adults: young children age 2-9 years, adolescent age 9-19 years; adults $19-50$ years and adults 51 years and older; and for males and females separately there were still no significant differences

Table 4 Healthy Eating Index (HEI) - 2010 total score for children and adult lunch meat consumers and non-consumers (NHANES 2007-2010) by age and gender subgroups. Values are means \pm SEM. Values are adjusted for age, gender, ethnicity, poverty income ratio, physical activity level, current smoking status, alcohol (only for adults), and kcal

\begin{tabular}{|c|c|c|c|c|}
\hline \multirow[t]{2}{*}{ Population subgroup } & \multirow[t]{2}{*}{$N$} & \multicolumn{3}{|c|}{ Total HEI 2010 score } \\
\hline & & Non-consumer & Consumer & $P$ Value \\
\hline \multicolumn{5}{|c|}{ Children age $2-18$ years } \\
\hline Gender combined & 5099 & $46.02 \pm 0.41$ & $45.71 \pm 0.56$ & 0.6187 \\
\hline Female & 2455 & $46.14 \pm 0.54$ & $46.44 \pm 0.74$ & 0.7489 \\
\hline Male & 2644 & $45.88 \pm 0.49$ & $45.06 \pm 0.83$ & 0.3664 \\
\hline \multicolumn{5}{|c|}{ Young Children age 2-8 years } \\
\hline Gender combined & 2476 & $50.00 \pm 0.43$ & $48.53 \pm 0.71$ & 0.0782 \\
\hline Female & 1163 & $49.96 \pm 0.64$ & $49.39 \pm 0.92$ & 0.6418 \\
\hline Male & 1313 & $50.04 \pm 0.57$ & $47.32 \pm 1.24$ & 0.0776 \\
\hline \multicolumn{5}{|c|}{ Adolescent age 9-18 years } \\
\hline Gender combined & 2623 & $42.92 \pm 0.52$ & $43.75 \pm 0.85$ & 0.3518 \\
\hline Female & 1292 & $43.44 \pm 0.70$ & $44.55 \pm 1.20$ & 0.4152 \\
\hline Male & 1331 & $42.36 \pm 0.63$ & $42.99 \pm 1.00$ & 0.5198 \\
\hline \multicolumn{5}{|c|}{ Adults age 19 years \& older } \\
\hline Gender combined) & 10216 & $49.40 \pm 0.43$ & $48.79 \pm 0.51$ & 0.2010 \\
\hline Female & 5116 & $50.60 \pm 0.56$ & $50.54 \pm 0.73$ & 0.9387 \\
\hline Male & 5100 & $48.12 \pm 0.38$ & $47.00 \pm 0.54$ & 0.0193 \\
\hline \multicolumn{5}{|l|}{ Adults age $19-50$ years } \\
\hline Gender combined & 5359 & $46.79 \pm 0.48$ & $47.19 \pm 0.70$ & 0.5271 \\
\hline Female & 2703 & $47.64 \pm 0.63$ & $48.85 \pm 1.00$ & 0.2401 \\
\hline Male & 2656 & $45.95 \pm 0.48$ & $45.65 \pm 0.82$ & 0.6456 \\
\hline \multicolumn{5}{|c|}{ Adults age 51 years \& older } \\
\hline Gender combined & 4857 & $53.24 \pm 0.53$ & $51.23 \pm 0.68$ & 0.0124 \\
\hline Female & 2413 & $54.64 \pm 0.58$ & $52.95 \pm 0.82$ & 0.1083 \\
\hline Male & 2444 & $51.61 \pm 0.54$ & $49.30 \pm 0.95$ & 0.0319 \\
\hline
\end{tabular}

$(P>0.01)$ in HEI 2010 scores between consumers and non-consumers (Table 4).

Although the total HEI 2010 was similar for lunch meat consumers and non-consumers among children and adults, there were differences in the scores for components of HEI 2010 (Table 5). In children age 2-19 years, HEI components scores were significantly higher $(P<0.01)$ for total fruit $(12.6 \%)$, whole fruit $(17.4 \%)$, whole grains (30.6\%), dairy (9.0\%), and total protein foods $(18.8 \%)$ in lunch meat consumers while component scores for seafood and plant protein $(-25.6 \%)$, fatty acid ratio $(-18.5 \%)$ and sodium $(-38.3 \%)$ were significantly lower $(P<0.01)$ compared to non-consumers. Similarly, among adults, the HEI components scores were significantly higher $(P<0.01)$ for total fruit $(9.1 \%)$, whole grains $(31.1 \%)$, dairy $(16.2 \%)$, and total protein foods $(9.8 \%)$ in lunch meat consumers while component scores for greens and beans $(-19.0 \%)$, seafood and plant protein $(-18.8 \%)$, fatty acid ratio $(-12.8 \%)$ and sodium $(-41.8 \%)$ were significantly lower $(P<0.01)$ compared to non-consumers (Table 5).

There were no differences in any studied physiological measures (body weight, waist circumference, body mass index, systolic blood pressure, diastolic blood pressure, fasting plasma glucose, fasting plasma insulin, C-reactive protein, fasting triglycerides, total cholesterol, LDLcholesterol, HDL-cholesterol, and apolipoprotein B) associated with lunch meat consumption in children age 2-18 years and in adults age 19 years and older (Table 6). The differences between consumers and non-consumers remained non-significant $(P>0.01)$ when the data was further analyzed for different age groups for children and adults: young children age 2-9 years, adolescent age 9-19 years; adults 19-50 years and adults 51 years and older; and for males and females (data not presented).

The odds ratios of health related conditions were also similar (overlapping $95 \% \mathrm{CI}$ ) for lunch meat consumers compared to non-consumers for both children and adults (Table 7). Lunch meat consumers did not show any significant differences in odds ratios compared with non-consumers even when the data was further analyzed for different age groups for children: young children age 2-9 years, adolescent age 9-19 years; for adults: age 19-50 years and 51 years and older; and for males and females (data not presented).

\section{Discussion}

This is the first report to investigate lunch meat consumption in the U.S. population and explore its relationships with nutrient intake, diet quality and physiological markers of health. In the present study, we combined NHANES 2007-2008 and NHANES 2009-2010 data and the combined data set provided a sample size of 
Table 5 Healthy Eating Index (HEI) - 2010 total score and component scores of children $(n=5099)$ and adult $(n=10216)$ lunch meat consumers and non-consumers (NHANES 2007-2010 gender combined data). Values are means \pm SEM. Values are adjusted for age, gender, ethnicity, poverty income ratio, physical activity level, current smoking status, alcohol (only for adults), and kcal

\begin{tabular}{|c|c|c|c|c|c|c|}
\hline \multirow[t]{2}{*}{ Variables } & \multicolumn{3}{|c|}{ Children (2-18 years old) } & \multicolumn{3}{|c|}{ Adults (19 years and older) } \\
\hline & Non-consumers & Consumers & $P$ Value for difference & Non-consumers & Consumers & $P$ Value for difference \\
\hline HEl-2010 Total Score & $46.02 \pm 0.41$ & $45.71 \pm 0.56$ & 0.6187 & $49.40 \pm 0.43$ & $48.79 \pm 0.51$ & 0.2010 \\
\hline Component 1 (Total Vegetables) & $2.10 \pm 0.04$ & $1.95 \pm 0.08$ & 0.0821 & $3.05 \pm 0.04$ & $2.89 \pm 0.05$ & 0.0100 \\
\hline Component 2 (Greens \& Beans) & $0.68 \pm 0.05$ & $0.52 \pm 0.08$ & 0.0902 & $1.28 \pm 0.05$ & $1.03 \pm 0.06$ & 0.0001 \\
\hline Component 3 (Total Fruit) & $2.51 \pm 0.06$ & $2.83 \pm 0.11$ & 0.0059 & $2.13 \pm 0.04$ & $2.32 \pm 0.06$ & 0.0039 \\
\hline Component 4 (Whole Fruit) & $2.24 \pm 0.07$ & $2.63 \pm 0.15$ & 0.0095 & $2.07 \pm 0.05$ & $2.28 \pm 0.08$ & 0.0212 \\
\hline Component 5 (Whole Grains) & $1.97 \pm 0.07$ & $2.57 \pm 0.13$ & 0.0007 & $2.23 \pm 0.08$ & $2.93 \pm 0.10$ & $<0.0001$ \\
\hline Component 6 (Dairy) & $6.97 \pm 0.09$ & $7.60 \pm 0.15$ & 0.0013 & $5.10 \pm 0.07$ & $5.92 \pm 0.11$ & $<0.0001$ \\
\hline Component 7 (Total Protein Foods) & $3.46 \pm 0.04$ & $4.11 \pm 0.05$ & $<0.0001$ & $4.16 \pm 0.02$ & $4.57 \pm 0.02$ & $<0.0001$ \\
\hline Component 8 (Seafood \& Plant Protein) & $1.37 \pm 0.04$ & $1.02 \pm 0.09$ & 0.0013 & $2.07 \pm 0.04$ & $1.68 \pm 0.07$ & $<0.0001$ \\
\hline Component 9 (Fatty Acid Ratio) & $3.88 \pm 0.07$ & $3.16 \pm 0.16$ & 0.0004 & $4.98 \pm 0.06$ & $4.34 \pm 0.13$ & 0.0002 \\
\hline Component 10 (Sodium) & $5.17 \pm 0.11$ & $3.19 \pm 0.17$ & $<0.0001$ & $4.39 \pm 0.06$ & $2.55 \pm 0.09$ & $<0.0001$ \\
\hline Component 11 (Refined Grains) & $5.30 \pm 0.09$ & $5.00 \pm 0.20$ & 0.1818 & $6.21 \pm 0.06$ & $6.05 \pm 0.15$ & 0.2908 \\
\hline Component 12 (SoFAAS Calories) & $10.36 \pm 0.13$ & $11.14 \pm 0.31$ & 0.0224 & $11.73 \pm 0.17$ & $12.22 \pm 0.19$ & 0.0167 \\
\hline
\end{tabular}

over 15 thousand adults and children. Lunch meats, also known as deli meat or cold cuts, are precooked or cured meat that are sliced and used to make a convenient sandwich filling or salad topping. The NHANES 20072010 data showed that almost one-fifth of the population (18\% children age $2-18$ and $19 \%$ adults age 19 years and older) consumed lunch meat on the day of the recall.
Both adults and children consumers of lunch meat consumed significantly more calories as well as protein compared to their respective non-consumers. Additionally, they consumed more energy adjusted calcium, potassium and thiamine compared to non-consumers. Calcium and potassium are termed as "nutrients of concern" by the Dietary Guidelines for Americans, 2010 [1]. Current intake of calcium is estimated to be below the

Table 6 Association of lunch meat consumption with physiological measures in children and adults - NHANES 2007-2010. Values are means \pm SEM. Values are adjusted for age, gender, ethnicity, poverty income ratio, physical activity level, current smoking status, alcohol (only for adults) and weight (only for variable not related to weight)

\begin{tabular}{|c|c|c|c|c|}
\hline Physiological variables & $\mathrm{N}$ & Non-consumer & Consumer & $P$ Value \\
\hline \multicolumn{5}{|l|}{ Children age $2-18$ years } \\
\hline BMI Z Score & 5046 & $0.44 \pm 0.03$ & $0.48 \pm 0.05$ & 0.4464 \\
\hline \multicolumn{5}{|l|}{ Adults age 19 years and older } \\
\hline Weight (kg) & 10,108 & $82.19 \pm 0.35$ & $82.08 \pm 0.65$ & 0.8859 \\
\hline Body Mass Index (kg/m²) & 10,097 & $28.69 \pm 0.12$ & $28.73 \pm 0.21$ & 0.8631 \\
\hline Waist Circumference (cm) & 9,821 & $98.10 \pm 0.30$ & $97.98 \pm 0.53$ & 0.8631 \\
\hline BP Diastolic (mm Hg) & 9,761 & $70.63 \pm 0.37$ & $70.42 \pm 0.44$ & 0.5349 \\
\hline BP Systolic (mm Hg) & 9,802 & $121.28 \pm 0.29$ & $121.51 \pm 0.43$ & 0.6721 \\
\hline Total cholesterol (mg/dL) & 9,604 & $196.95 \pm 0.73$ & $196.35 \pm 1.44$ & 0.6160 \\
\hline LDL-cholesterol (mg/dL) & 4,280 & $116.68 \pm 0.78$ & $113.83 \pm 1.41$ & 0.0539 \\
\hline HDL-cholesterol (mg/dL) & 9,604 & $52.52 \pm 0.33$ & $52.57 \pm 0.42$ & 0.8991 \\
\hline Triglyceride (mg/dL) & 4,359 & $129.81 \pm 1.91$ & $131.96 \pm 3.87$ & 0.6182 \\
\hline Apolipoprotein (B) (mg/dL) & 4,357 & $92.34 \pm 0.66$ & $90.47 \pm 1.03$ & 0.0620 \\
\hline C-reactive protein (mg/dL) & 9,636 & $0.37 \pm 0.01$ & $0.42 \pm 0.04$ & 0.2105 \\
\hline Glucose, plasma (mg/dL) & 4,391 & $104.59 \pm 0.61$ & $106.42 \pm 1.29$ & 0.2162 \\
\hline Insulin $(\mu \mathrm{U} / \mathrm{mL})$ & 4,332 & $12.70 \pm 0.23$ & $12.28 \pm 0.27$ & 0.2582 \\
\hline
\end{tabular}


Table 7 Association of lunch meat consumption with odds ratios of weight/waist status and other risk factors in children and adults - NHANES 2007-2010. Values are adjusted for age, gender, ethnicity, poverty income ratio, physical activity level, current smoking status, alcohol (for adults only), and weight (only for variable not related to weight)

\begin{tabular}{|c|c|c|c|c|}
\hline \multirow[t]{2}{*}{ Variables } & \multirow[t]{2}{*}{$\mathrm{N}$} & \multicolumn{3}{|c|}{ Odds ratio $(95 \% \mathrm{Cl})$} \\
\hline & & Non-consumer & Consumer & $P$ Value \\
\hline \multicolumn{5}{|l|}{ Children age $2-18$ years } \\
\hline Obese & 5046 & 1.00 & $1.14(0.90,1.44)$ & 0.2577 \\
\hline Overweight & 5046 & 1.00 & $1.01(0.70,1.47)$ & 0.9560 \\
\hline Overweight or Obese & 5046 & 1.00 & $1.09(0.85,1.40)$ & 0.4693 \\
\hline \multicolumn{5}{|l|}{ Adults age 19 years and older } \\
\hline Obese & 10,097 & 1.00 & $0.97(0.82,1.16)$ & 0.7518 \\
\hline Overweight & 10,097 & 1.00 & $0.89(0.75,1.04)$ & 0.1391 \\
\hline Overweight or Obese & 10,097 & 1.00 & $0.86(0.74,1.01)$ & 0.0582 \\
\hline Waist Circumference Elevated & 9,821 & 1.00 & $0.88(0.73,1.05)$ & 0.1519 \\
\hline BP Elevated & 9,971 & 1.00 & $0.96(0.78,1.18)$ & 0.6777 \\
\hline HDL Reduced & 9,808 & 1.00 & $1.01(0.88,1.15)$ & 0.9306 \\
\hline LDL Elevated & 4,359 & 1.00 & $0.88(0.70,1.10)$ & 0.2594 \\
\hline Triglycerides Elevated & 4,420 & 1.00 & $1.03(0.83,1.28)$ & 0.7786 \\
\hline Glucose Elevated & 4,443 & 1.00 & $1.13(0.91,1.40)$ & 0.2699 \\
\hline Metabolic Syndrome & 7,229 & 1.00 & $0.98(0.75,1.28)$ & 0.8699 \\
\hline
\end{tabular}

Estimated Average Requirement for over $40 \%$ of the population and only about $3 \%$ population is currently consuming more than the Adequate Intake for potassium [10]. Adequate calcium status is important for optimal bone health and potassium helps lower the blood pressure. Dietary Guidelines for Americans, 2010 has recommended increasing intake of calcium and potassium [1]. Meat (especially lean meat) is considered as one of the most nutrient dense food [6]. Lunch meat consumers also had higher intakes of sodium compared to non-consumers. Excessive sodium intake has been related to high prevalence of high blood pressure [1]. Sodium intake estimated in this study was higher than the recommended 2,300 mg for both adult and children, irrespective of their being consumers or non-consumers. Potassium lowers blood pressure by blunting the adverse effects of sodium on blood pressure. However, it should be noted there were no significant differences in blood pressure between consumers and non-consumers for both adults and children.

The HEI 2010 scores of lunch meat consumers were not significantly different from those of non-consumers for both adults and children. The HEI is a measure of diet quality that indicates compliance/adherence of the diets to the recommendations of Dietary Guidelines for Americans, 2010. HEI is commonly used to evaluate diets including subpopulations [22] and food environments [23], to assess changes in the diet quality over time [24] and the efficacy of dietary interventions, and to validate other nutrition research tools and indexes
[25]. It has also been used in recent research to understand relationships between nutrients/foods/dietary patterns and health-related outcomes [26-29]. Lunch meat consumers had similar HEI 2010 scores as nonconsumers and the differences in HEI 2010 scores remained non-significant even when the data was further analyzed by age (young children, adolescent, adults and older adults) and gender groups (males and females) indicating that the diet quality of lunch meat consumers were similar to non-consumers for every age/gender group. These results suggest that lunch meats do not necessarily decrease average diet quality of adults and children. HEI 2010 has 12 components (9 for adequacy and 3 for moderation) each of which relate to the key recommendations of the Dietary Guidelines for Americans, 2010. Although the total HEI scores were not different for lunch meat consumers compared to non-consumers, there were some differences in the subcomponent scores which may provide insight into incorporating lunch meats into diets to help align with Dietary Guidelines Recommendations. For example, lower sodium lunch meat options may be considered and it appears that the use of cheese and whole grains are more common in lunch meat consumers thus improving HEI subcomponent scores for dairy and whole grains, respectively.

In the current study, lunch meat intake was not associated with any physiological measurements including BMI, blood pressure, blood lipids or blood sugar. The recently released Scientific Report of the Dietary Guidelines Advisory Committee 2015 indicated that dietary 
patterns consisting of lower consumption of red and processed meat were associated with positive health outcomes [10]. In an abstract the International Agency for Research on Cancer experts indicated that 34,000 to 50,000 cancer deaths per year worldwide may be attributable to diets high in processed meat and red meat respectively while air pollution, alcohol intake and tobacco smoking are responsible for 200,000, 600,000 and 1 million deaths per year worldwide respectively [30, 31]. The expert report concluded that each $50 \mathrm{~g}$ portion of processed meat eaten daily may increase the risk of colorectal cancer by $18 \%$, [30, 31]. It is impossible to accurately discern the contribution of one single food consumed with causation of cancer because it is impossible to separate an individual food from the confounding interactions of other potential carcinogenic "hazards" experienced over the course of a lifetime. Intake of processed meat was found to be associated with a higher risk of coronary heart disease (CHD) and type-2 diabetes [32]. In a meta-analysis, consumption of processed meats was associated with higher incidence of CHD and diabetes mellitus [33]. High intake of processed meat was also implicated with increased risk of early death, in particular due to cardiovascular diseases and cancer, in a recently published European epidemiological study [34]. However, most observational studies reported only a small increase in relative risk [6]. Industry efforts for the past 10 years have focused on simplification of ingredient lists. This "clean labeling" effort has resulted in significant changes regarding processing techniques applied to product development of luncheon meats. In the present study, we did not find any significant differences in physiological measures or in the odds ratio of all studied health related conditions between lunch meat consumers and nonconsumers (in fact, lunch meat consumers had better average physiological measures for lipids and overweight/ obesity risk in our findings.) Whether the lack of significant effect on physiological parameters is a result of using NHANES, an observational study; effect of presence of other dietary components such as fruits and vegetables, whole grain etc. in the diet of consumers; or whether lunch meats have evolved since the previously mentioned studies were published will have to await further research.

A limitation of this study is that cross-sectional studies cannot be used to determine cause and effect. Additionally, 24-h dietary recalls rely on participants' memory to self-report dietary intakes; and therefore data are subject to misreporting. Also the data used in this study was based on single 24-h dietary recall. Strengths of this study included the use of large nationally representative sample achieved through combining several sets of NHANES data releases and adjusting for numerous covariates, but even with these covariates some residual confounding may still exist.
Future research might consider comparing lunch meat consumers, with consumers of other meats and/or nonconsumers of meat. Additionally, when further data are available it might also be meritorious to conduct analyses comparing particular types of lunch meats (e.g., whole cut versus sectioned/formed, versus processed meat). Other work might examine further other items consumed with lunch meats and whether more healthy items could be identified.

\section{Conclusion}

In conclusion, results from this study suggest that lunch meat intake did not affect the overall diet quality while differences in certain subcomponents scores (dairy, whole grains and sodium) suggest there may be ways to incorporate lunch meats into healthy dietary patterns.

\section{Abbreviations}

BMI: Body Mass Index; HEl: Healthy Eating Index; MUFA: Mono unsaturated fatty acids; NHANES: National Health and Nutrition Examination Survey; PUFA: Poly unsaturated fatty acids; SEM: Standard errors of the mean; SFA: Saturated fatty acids.

\section{Competing interests}

SA and VLF are nutrition consultants and provide services to food industry. EPB is a faculty at North Dakota State University and also serves as academic consultant on the Food Safety, Human Nutrition, and Pork Quality

Committee, National Pork Board.

\section{Authors' contributions}

All authors participated in data analysis and interpretation. SA drafted the manuscript and all authors participated in revising and finalizing the manuscript. All authors read and approved the final manuscript.

\section{Acknowledgement}

The present study was funded by North American Meat Institute.

\section{Author details}

${ }^{1}$ NutriScience LLC, 901 Heatherwood Drive, East Norriton, PA 19403, USA.

${ }^{2}$ Nutrition Impact LLC, Battle Creek, MI, USA. ${ }^{3}$ Animal Sciences, North Dakota State University, Fargo, ND, USA.

Received: 9 July 2015 Accepted: 23 December 2015

Published online: 30 December 2015

\section{References}

1. U.S. Department of Health and Human Services and USDA. Dietary Guidelines for Americans, 2010. 7th ed. Washington, DC: GPO; 2011.

2. USDA. How Much Food from the Protein Foods Group is Needed Daily? 2010. http://www.choosemyplate.gov/food-groups/protein-foods-amount.pdf. Accessed February 2015.

3. Biesalski HK. Meat as a component of a healthy diet - are there any risks or benefits if meat is avoided in the diet? Meat Sci. 2005;70:509-24.

4. O'Neil CE, Zanovec M, Keast DR, Fulgoni 3rd VL, Nicklas TA. Nutrient contribution of total and lean beef in diets of US children and adolescents: National Health and Nutrition Examination Survey 1999-2004. Meat Sci. 2011;87:250-6.

5. Murphy MM, Spungen JH, Bi X, Barraj LM. Fresh and fresh lean pork are substantial sources of key nutrients when these products are consumed by adults in the United States. Nutr Res. 2011;31:776-83.

6. Klurfeld DM. Research gaps in evaluating the relationship of meat and health. Meat Sci. 2015. doi:10.1016/j.meatsci.2015.05.022.

7. Pereira PMCC, Vicente AFRB. Meat nutritional composition and nutritive role in the human diet. Meat Sci. 2013;93:586-92.

8. Wyness $L$. The role of red meat in the diet: nutrition and health benefits Proc Nutr Soc. 2015:8:1-6. [Epub ahead of print]. 
9. Nohr D, Biesalski HK. 'Mealthy' food: meat as a healthy and valuable source of micronutrients. Animal. 2007;1:309-316.

10. USDA \& DHHS. Scientific Report of the Dietary Guidelines Advisory Committee, 2015 [internet]. 2015 [updated 02/24/2015; cited 2/24/2015] Available from: http://health.gov/dietaryguidelines/2015-scientific-report/

11. Centers for Disease Control and Prevention (CDC), National Center for Health Statistics. National Health and Nutrition Examination Survey. Hyattsville, MD: National Center for Health Statistics. [cited 15 July 2013] Available from: http://www.cdc.gov/nchs/nhanes/about_nhanes.htm.

12. USDA, Agricultural Research Service, Food Surveys Research Group: Food and Nutrient Database for Dietary Studies, 4.1. Beltsville: 2010.

13. Ahuja JKA, Montville JB, Omolewa-Tomobi G, Heendeniya KY, Martin CL, Steinfeldt LC, et al. USDA Food and Nutrient Database for Dietary Studies, 5. 0. Beltsville: Department of Agriculture, Agricultural Research Service, Food Surveys Research Group; 2012.

14. U.S. Department of Agriculture, Agricultural Research Service. USDA National Nutrient Database for Standard Reference, Release 22. Nutrient Data Laboratory Home Page; 2009. http://www.ars.usda.gov/ba/bhnrc/ndl. Accessed July 2013.

15. U.S. Department of Agriculture, Agricultural Research Service. USDA National Nutrient Database for Standard Reference, Release 24. Nutrient Data Laboratory Home; 2011. http://www.ars.usda.gov/ba/bhnrc/ndl. Accessed July 2013.

16. U.S. Department of Agriculture, Agricultural Research Service. USDA Food Patterns Equivalent Database. http://www.ars.usda.gov/Services/docs. htm?docid=23871. Accessed July 2013.

17. Bowman SA, Friday JE, Moshfegh A. MyPyramid Equivalents Database. Food Surveys Research Group Web site: USDA Agricultural Research Service; 2008. Available at: http://www.ars.usda.gov/Services/docs.htm?docid=17565. Accessed July 2013.

18. Guenther PM, Casavale KO, Reedy J, Kirkpatrick SI, Hiza HA, Kuczynski KJ, et al. Update of the Healthy Eating Index: HEl-2010. J Acad Nutr Diet. 2013;113:569-80.

19. National Cancer Institute. Healthy Eating Index. HEl tools for researchers. (updated April 2014. http://appliedresearch.cancer.gov/hei/tools.html. Accessed April 2014

20. Centers of Disease Control and Prevention. 2000 CDC growth charts for the United States: methods and development. Vital Health Stat. 2002:11:246.

21. National Cholesterol Education Program: National heart, lung, and blood institute. National institutes of health. Detection, evaluation, and treatment of high blood cholesterol in adults (adult treatment panel III); 2002. $\mathrm{NIH}$ Publication No. 02-5215.

22. Hiza HA, Casavale KO, Guenther PM, Davis CA. Diet quality of Americans differs by age, sex, race/ethnicity, income, and education level. J Acad Nutr Diet. 2013;113:297-306.

23. Reedy J, Krebs-Smith SM, Bosire C. Evaluating the food environment: application of the Healthy Eating Index-2005. Am J Prev Med. 2010;38:465-71.

24. Juan WY, Guenther PM, Kott PS. Nutrition Insight 41. Alexandria: United States Department of Agriculture Center for Nutrition Policy and Promotion; 2008. Diet quality of older Americans in 1994-96 and 2001-02 as measured by the Healthy Eating Index-2005.

25. Fulgoni VL, Keast DR, Drewnowski A. Development and validation of the Nutrient-rich Foods Index: a tool to measure nutritional quality of foods. J Nutr. 2009;139:1549-54.

26. Nicklas TA, O'Neil CE, Fulgoni VL. Diet quality is inversely related to cardiovascular risk factors in adults. J Nutr. 2012;142:2112-8.

27. Chiuve S, Fung T, Rimm E, Hu F, McCullough M, Wang M, et al. Alternative dietary indices both strongly predict risk of chronic disease. J Nutr. 2012; 142:1009-18.

28. Reedy J, Mitrou PN, Krebs-Smith SM, Wirfält E, Flood A, Kipnis V, et al. Index-based dietary patterns and risk of colorectal cancer: the NIH-AARP Diet and Health Study. Am J Epidemiol. 2008;168:38-48.

29. O'Neil CE, Nicklas TA, Rampersaud GC, Fulgoni VL. One hundred percent orange juice consumption is associated with better diet quality, improved nutrient adequacy, and no increased risk for overweight/obesity in children. Nutr Res. 2011;31:673-82.

30. Bouvard V, Loomis D, Guyton KZ, Grosse Y, Ghissassi FE, Benbrahim-Tallaa L, et al. Carcinogenicity of consumption of red and processed meat. Lancet Oncol. 2015. doi:10.1016/S1470-2045(15)00444-1.

31. World Health Organization. Q\&A on the carcinogenicity of the consumption of red meat and processed meat. (updated October 2015). http://www.who.int/features/qa/cancer-red-meat/en/. Accessed Octobe 2015

32. van Dam RM, Willett WC, Rimm EB, Stampfer MJ, Hu FB. Dietary fat and meat intake in relation to risk of type 2 diabetes in men. Diabetes Care. 2002;25:417-24.

33. Micha R, Wallace SK, Mozaffarian D. Red and processed meat consumption and risk of incident coronary heart disease, stroke, and diabetes mellitus: A systematic review and meta-analysis. Circulation. 2010;121:2271-83.

34. Rohrmann R, Overvad K, Bueno-de-Mesquita HB, Jakobsen MU, Egeberg R, Tjønneland A, et al. Meat consumption and mortality - results from the European Prospective Investigation into Cancer and Nutrition. BMC Med. 2013;11:63. doi:10.1186/1741-7015-11-63.

\section{Submit your next manuscript to BioMed Central and we will help you at every step:}

- We accept pre-submission inquiries

- Our selector tool helps you to find the most relevant journal

- We provide round the clock customer support

- Convenient online submission

- Thorough peer review

- Inclusion in PubMed and all major indexing services

- Maximum visibility for your research

Submit your manuscript at www.biomedcentral.com/submit
) Biomed Central 